\title{
The decline of Norwegian kittiwake populations: modelling the role of ocean warming
}

\author{
Hanno Sandvik ${ }^{1, *}$, Tone K. Reiertsen ${ }^{2,3}$, Kjell Einar Erikstad ${ }^{1,3}$, \\ Tycho Anker-Nilssen ${ }^{4}$, Robert T. Barrett ${ }^{2}$, Svein-Håkon Lorentsen ${ }^{4}$, Geir Helge \\ Systad $^{3}$, Mari S. Myksvoll ${ }^{5}$ \\ ${ }^{1}$ Centre for Biodiversity Dynamics (CBD), Department of Biology, Norwegian University of Science and Technology (NTNU), \\ 7491 Trondheim, Norway \\ ${ }^{2}$ Tromsø Museum, University of Tromsø, PO Box 6050 Langnes, 9037 Tromsø, Norway \\ ${ }^{3}$ Norwegian Institute for Nature Research (NINA), FRAM - High North Research Centre for Climate and the Environment, \\ 9296 Tromsø, Norway \\ ${ }^{4}$ Norwegian Institute for Nature Research (NINA), PO Box 5685 Sluppen, 7485 Trondheim, Norway \\ ${ }^{5}$ Institute for Marine Research, PO Box 1870 Nordnes, 5817 Bergen, Norway
}

\begin{abstract}
The black-legged kittiwake Rissa tridactyla is a pelagic seabird whose population has recently declined in most parts of the North Atlantic and which is red-listed in most bordering countries. To investigate a possible cause for this decline, we analysed the population dynamics of 5 kittiwake colonies along the Norwegian coast, ranging from $62^{\circ}$ to $71^{\circ} \mathrm{N}$, over the last 20 to $35 \mathrm{yr}$. By quantifying the importance of sea surface temperatures (SST) in relevant areas of the North Atlantic, we tested the importance of climatic conditions throughout the populations' annual cycles. We found no synchrony among colonies; however, SST affected population dynamics, explaining between $6 \%$ and $37 \%$ (average $18 \%$ ) of the variation in annual population growth rate. While dynamics of the southerly colonies were mainly affected by winter conditions in the Grand Banks area, dynamics of the northernmost colonies were dominated by autumn conditions off Svalbard. Negative slopes indicated stronger population decline under warmer ocean conditions. Population dynamics were affected both via adult survival and offspring recruitment, as evidenced by the presence of unlagged effects as well as effects lagged by the age at recruitment. Finally, we performed population viability analyses taking into account the projected warming trends for the future. The median time to extinction of the Norwegian colonies was 52 to $181 \mathrm{yr}$ without considering covariates; 45 to $94 \mathrm{yr}$ when considering the effects of SST but ignoring future warming; and 10 to $48 \mathrm{yr}$ when ocean warming, based on a 'business as usual' scenario, was taken into account.
\end{abstract}

KEY WORDS: Global warming $\cdot$ Non-breeding distribution $\cdot$ Population dynamics $\cdot$ Population viability analysis $\cdot$ Rissa tridactyla $\cdot$ Sea surface temperature

\section{INTRODUCTION}

Predicting the impact of human activities, including global climate change, on the biosphere has become one of the most important efforts in ecology. Ecosystems worldwide are changing rapidly as a consequence of anthropogenic impacts such as global warming (IPCC 2007), yet our understanding of the consequences of these changes on populations is limited. To be able to predict population trajectories, it is crucial to understand the mechanisms underlying variation of, and co-variation among, populations. Population fluctuations are determined by parameters such as intrinsic population growth rate and carrying capacity, as well as by stochastic fluctuations in the environment (Lande et al. 2003). Furthermore, temporal variation in climate and other environmental variables may synchronise population 
fluctuations over large distances (Moran 1953, Bjørnstad et al. 1999, Lande et al. 1999, Post \& Forchhammer 2002). Population synchrony, defined as the inter-annual correlation of population growth rates across colonies, can therefore indicate the presence of environmental factors affecting population dynamics on large spatial scales. Moreover, a high degree of inter-annual synchrony in population fluctuations increases the risk of local and global extinction (Esler 2000, Engen et al. 2002). Herein lies the main importance of population synchrony for population management.

In seabirds, knowledge about their distribution outside the breeding season has for a long time been a limiting factor in analysing and understanding the importance of environmental conditions for population processes (e.g. Smith \& Gaston 2012). Seabirds are normally philopatric and return to the same breeding colony each year, but may disperse over vast ocean ranges during the rest of the year (e.g. Egevang et al. 2010, Frederiksen et al. 2012). Quantitative analyses of environmental conditions during non-breeding have only recently become feasible through advances in tracking technologies, such as miniaturized yearround light-based tracking devices (GLS loggers or geolocators; Phillips et al. 2004, González-Solís et al. 2007, Egevang et al. 2010, Seavy et al. 2012).

We here use the novel knowledge of non-breeding distribution (Frederiksen et al. 2012) to search for environmental covariates explaining population dynamics of the black-legged kittiwake Rissa tridactyla (hereafter called kittiwake) in Norway. Kittiwake numbers have declined over most of the North Atlantic over the last 2 decades, particularly in the North Sea and adjacent areas (Frederiksen 2010). According to the IUCN Red List, the species is of least concern globally; in national Red Lists, however, it is currently listed as near threatened in Denmark, France and Svalbard, as vulnerable (or 'amber') in the Faroes, Greenland, Great Britain and Ireland and as endangered in Norway and Sweden (Wind \& Pihl 2004, Fosaa et al. 2005, Boertman 2007, Lynas et al. 2007, Eaton et al. 2009, Gärdenfors 2010, Kålås et al. 2010, UICN France et al. 2011).

At a study colony in the North Sea, the decline was caused by low reproductive success as well as low adult survival (Frederiksen et al. 2004), both apparently linked to increasing sea temperatures affecting their main prey (Frederiksen et al. 2006). To understand whether the ocean-wide decline of kittiwakes is governed by a common factor, it is important to establish whether these findings can be generalised to kittiwake populations in other areas.
We here study the dynamics of 5 kittiwake populations along the coast of Norway in order to address 4 questions: (1) Is there any population synchrony between the colonies? (2) How are the population dynamics related to the local climatic conditions (sea surface temperature [SST]) in the areas where the birds stay during different parts of their annual cycle? (3) Through which demographic trait (adult survival or offspring recruitment) is climate affecting the population growth rate? (4) How will the predicted future warming trend affect the viability of the populations?

\section{MATERIAL AND METHODS}

\subsection{Population monitoring}

Kittiwakes breed in many places along the Norwegian coast. We analysed population counts from the 5 kittiwake Rissa tridactyla colonies that are part of the long-term Norwegian Monitoring Programme for Seabirds, covering the geographic range from the southern Norwegian Sea to the Barents Sea (Fig. 1). From southwest (boreal climate) to northeast (Arctic climate), the colonies included were Runde $\left(62^{\circ} 24^{\prime} \mathrm{N}\right.$, $\left.5^{\circ} 38^{\prime} \mathrm{E}\right)$, Sklinna ( $\left.65^{\circ} 12^{\prime} \mathrm{N}, 10^{\circ} 59^{\prime} \mathrm{E}\right)$, Vedøy ( $67^{\circ} 29^{\prime} \mathrm{N}$, $\left.12^{\circ} 1^{\prime} \mathrm{E}\right)$, Hjelmsøya $\left(71^{\circ} 4^{\prime} \mathrm{N}, 24^{\circ} 43^{\prime} \mathrm{E}\right)$ and Hornøya $\left(70^{\circ} 23^{\prime} \mathrm{N}, 31^{\circ} 9^{\prime} \mathrm{E}\right)$.

The populations were monitored according to standardised methods (e.g. Walsh et al. 1995) using apparently occupied nests or nest sites (AON) as the counting unit. At Sklinna, the whole colony was counted, while averaged counts in randomly selected study plots were used in the other colonies. Annual estimates of AONs were based on a total count made in 2010/2011 and the annual rates of change documented in the monitoring plots. The AONs in the study plots represented $1.1 \%$ (10 study plots), $100 \%$ (whole colony count), $3.7 \%$ (6 study plots), $5.2 \%$ (5 study plots) and $12.3 \%$ (9 study plots) of the total population in Runde, Sklinna, Vedøy, Hjelmsøya and Hornøya, respectively. All counts were made late in the incubation period or early in the chick period.

Colony sizes varied by 3 orders of magnitude among colonies, ranging from 170 pairs in Sklinna to 158000 in Runde in 1980. All 5 populations declined during the monitoring period that spanned 20 to $35 \mathrm{yr}$ (Fig. 2). The breeding population at Sklinna went extinct in 2011; in our models, we disregarded all counts at this colony after 2001, when population size for the first time dropped below 20 breeding pairs. 


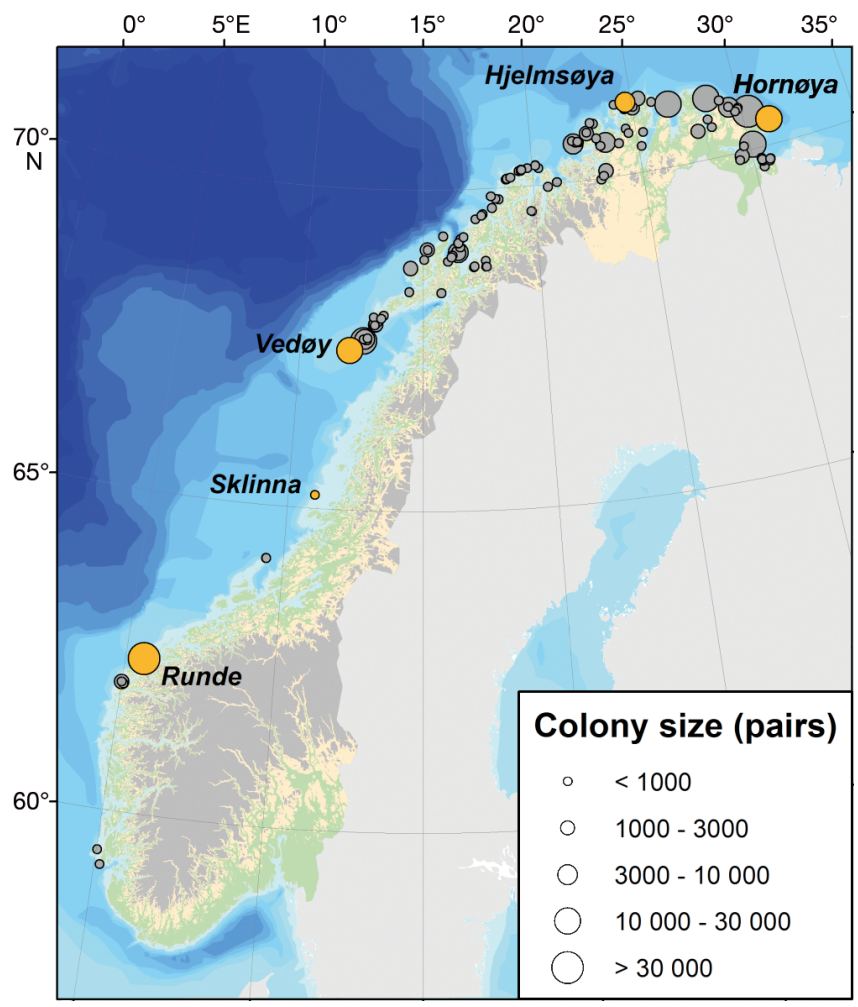

Fig. 1. Map of Norway showing all registered breeding colonies of black-legged kittwakes. The 5 study colonies are highlighted (orange). The size of the circles indicates the number of apparently occupied nests in 2005

\subsection{Population models}

Population dynamics of the 5 colonies were density-independent, as evidenced by the absence of any negative correlation between annual growth rates $r_{t}$ and population sizes $N_{t}$ (all correlation coefficients $\mathrm{R}>-0.25$, all $\mathrm{p}>0.3$; see the Supplement at www.int-res.com/articles/suppl/c061p091_supp. pdf for density-dependent models). We therefore used Brownian population models of the following form:

$$
\ln N_{t+1}=\ln N_{t}+\bar{r}-\frac{1}{2} \sigma_{\mathrm{d}}^{2} N_{t}^{-1}+\sum \beta_{i} X_{i, t}+\varepsilon_{t}
$$

with $\beta_{i}$ as the slope of the $i$ th environmental covariate $X_{i} ; \varepsilon$ is the environmental noise, i.e. an independent variable with zero mean and variance $\sigma_{\mathrm{e}}^{2}$ (environmental variance); $N_{t}$ is the population size in year $t_{i} \bar{r}$ is the long-term intrinsic population growth rate; $\sigma_{\mathrm{d}}^{2}$ is the demographic variance; $X_{i, t}$ is the environmental covariate $i$ in year $t$. The parameters $\beta_{i}, \bar{r}$ and $\sigma_{\mathrm{e}}^{2}$ were estimated from the population time series using maximum likelihood such that the log-likelihood

$$
\ln L=-\frac{1}{2} \sum_{k=2}^{n}\left\{\left[\ln N_{k}-E\left(\ln N_{k}\right)\right]^{2} \sigma^{-2}+\ln \left(2 \pi \sigma^{2}\right)\right\}
$$

was maximised over the $n$ elements of the time series (Sæther et al. 2009), where $E\left(\ln N_{k}\right)$ is the predicted log-population size based on the observed population size $N_{k-1}$ and Eq. (1), and $\sigma^{2}=\sigma_{\mathrm{e}}^{2}+\sigma_{\mathrm{d}}^{2} / N_{t}$. In the absence of estimates of life-time reproductive success of the 5 colonies, demographic variance was assumed to be 0.1 in all colonies, which is a realistic value for long-lived birds (Lande et al. 2003).

Population models were either fitted to one colony at a time or to all populations simultaneously. In the former case, the optimal set of parameters for each colony could be identified. The latter approach enabled us to test for the presence of synchrony and whether population parameters differed among colonies. It was carried out by modifying Eq. (1) in such a way that any of the parameters $\bar{r}, \sigma_{\mathrm{e}}^{2}$ or $\beta_{i}$ could be replaced by a vector of length 5, containing the growth rates, environmental variances or slopes for each of the 5 colonies; log-likelihood was maximised over the $\sum_{i=1}^{5} n_{i}$ elements of all 5 time series using Eq. (2). These modifications could be combined such that, for example, models with a common $\bar{r}$ and $\sigma_{\mathrm{e}}^{2}$, with a common $\bar{r}$ and 5 separate $\sigma_{\mathrm{e}}^{2}$, with a common $\sigma_{\mathrm{e}}^{2}$ and 5 separate $\bar{r}$, and with 5 separate $\bar{r}$ and $\sigma_{\mathrm{e}}^{2}$ could be compared with each other (likewise for each of the environmental variables $\beta_{i}$ ). If a model with a common parameter was preferred over a model with separate parameters, this indicated that this specific parameter did not differ significantly among colonies. Specifically, a common estimate for the slope $\beta$ would indicate that the corresponding environmental covariate is common to all 5 colonies and synchronises their dynamics.

Models with different parameterisations or covariates were compared using Akaike's information criterion corrected for small sample sizes $\left(\mathrm{AIC}_{\mathrm{C}}\right)$, preferring models with the lowest $\Delta \mathrm{AIC}_{\mathrm{C}}$ (or the highest $\mathrm{AIC}_{\mathrm{C}}$ weight or model likelihood; see Burnham \& Anderson 2002). Non-nested models within $2 \mathrm{AIC}_{\mathrm{C}}$ of each other were considered equally well supported. Confidence intervals were obtained by nonparametric bootstrapping of the model parameters using 10000 replicates.

\subsection{Population viability analyses}

Population viability analyses (PVA) were carried out separately for each colony. In each case, 10000 future population trajectories were modelled using Eq. (1). The quasi-extinction threshold was set at 20 pairs. Confidence limits around the median population trajectory were estimated as population predic- 

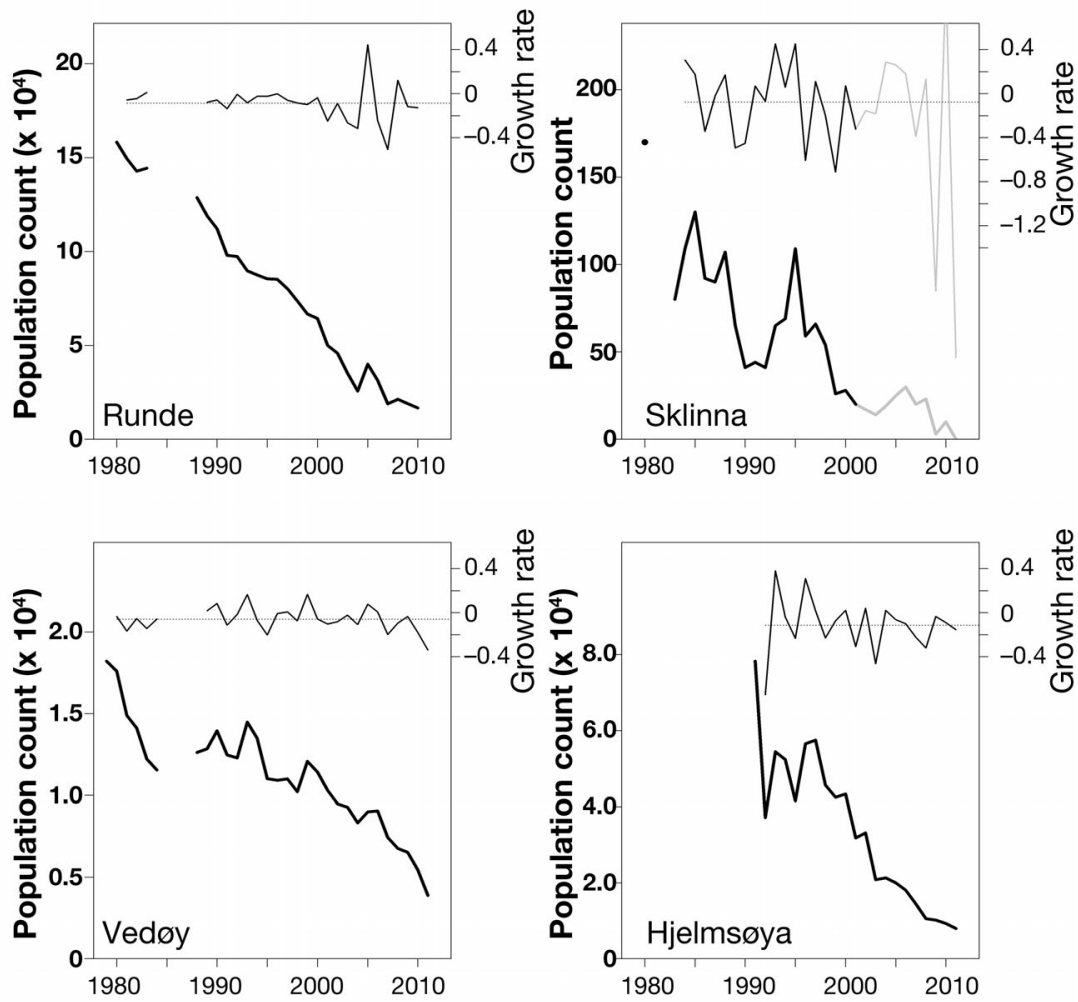

Fig. 2. Population trajectories (thick lines,

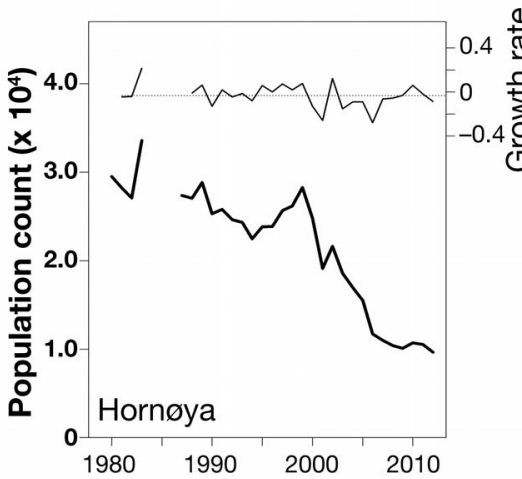

left-hand $y$-axes) and annual intrinsic population growth rates (thin lines, righthand $y$-axes) of 5 black-legged kittiwake breeding colonies along the Norwegian coast. Entities counted were apparently occupied nests. Note that the left-hand $y$ axes differ in scale (but not in intercept, which is zero in all cases). While the mean growth rates are rather similar (horizontal dotted lines), the variability differs both geographically and temporally. In the analyses, population counts at Sklinna have been disregarded after 2001 (grey lines; the dot in 1980 is a single population count)

2003). No PVA was performed for Sklinna because the population is already extinct and crossed the quasiextinction threshold of 20 pairs for the first time in 2001.

For each colony, a set of at least 3 different PVAs was carried out. The first PVA was based on the null population model, i.e. without covariates. The remaining PVAs were based on the estimates derived from the best population model(s) incorporating SST as a covariate; half of the latter PVAs assumed average SST to stay constant at the actual level of the years 2000 to 2011, the other half assumed average SST to increase in line with predictions of ocean warming (see Fig. 3). Using this approach, it is possible to directly compare the viability of each colony under different assumptions (effect of SST present vs. absent, and warming present vs. absent).

\subsection{Climatic variables}

The climatic covariate considered as an explanatory variable was SST, based on the Extended Reconstruction SST data set available on a $2^{\circ} \times 2^{\circ}$ grid (ERSST v 3b, NOAA 2012; cf. Smith et al. 2008). We considered spring and summer SSTs around each of the breeding colonies calculated as seasonal means (March to May and June to August, respectively) of the 2 grid cells adjacent to the colonies (Runde,

tion intervals. A population prediction interval is 'the stochastic interval that includes the unknown population size at a specified future time with a given probability or confidence level' (Lande et al. 2003, p. 108) and incorporates stochasticity as well as parameter uncertainty. The effects of demographic and environmental stochasticity are included via Eq. (1). Uncertainty about parameter estimates was taken into account by simulating the population time series using the estimated parameters 10000 times and re-estimating the parameters from each simulation. This method produces sampling distributions for all parameters $\left(\bar{r}, \sigma_{\mathrm{e}}^{2}\right.$ and $\left.\beta\right)$, from which a random set of population parameters is drawn, and accounts for the presence of sampling correlation (Lande et al.
62-64 ${ }^{\circ} \mathrm{N}, 2-8^{\circ} \mathrm{E}_{\text {; Sklinna, }} 64-66^{\circ} \mathrm{N}, 8-14^{\circ} \mathrm{E}_{\text {; }}$ Vedøy, $66-68^{\circ} \mathrm{N}, 8-14^{\circ} \mathrm{E}$; Hjelmsøya, $70-72^{\circ} \mathrm{N}, 22-28^{\circ} \mathrm{E}$; Hornøya, $70-72^{\circ} \mathrm{N}, 28-34^{\circ} \mathrm{E}$ ). SSTs for the nonbreeding season were taken from the following areas and periods: autumn SST off Svalbard was defined as the spatial mean September SST within the area 74$80^{\circ} \mathrm{N}, 14-36^{\circ} \mathrm{E}$; winter SST in the Grand Banks area as the spatial and seasonal mean SST during November to January within the area $40-62^{\circ} \mathrm{N}, 38-60^{\circ} \mathrm{W}$. These choices of areas and periods were based on the actual spatiotemporal distribution of kittiwakes from the relevant colonies outside the breeding season (Frederiksen et al. 2012).

SSTs were considered as covariates at different time lags, allowing for different biological explanations of 


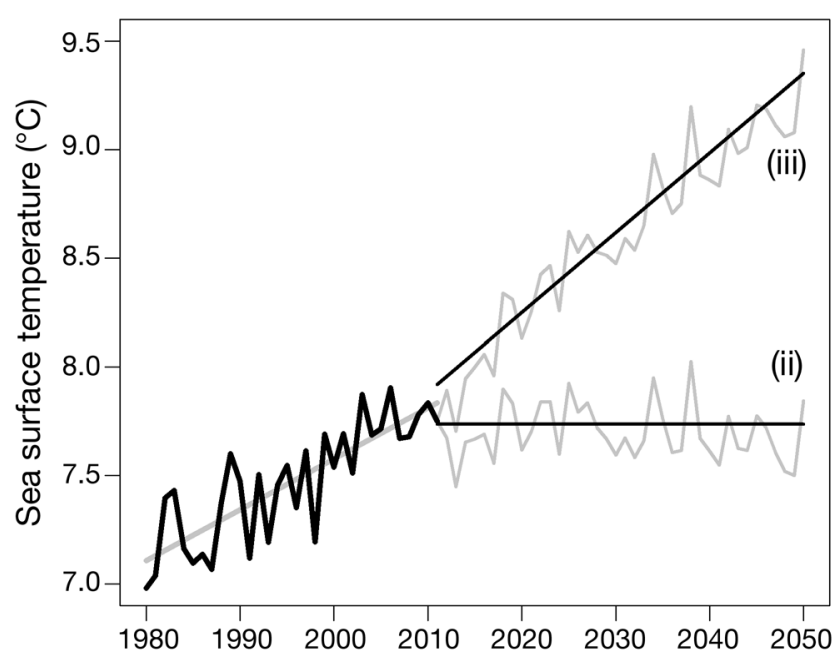

Fig. 3. Actual and predicted sea surface temperatures (SST) at Hornøya. The population viability analyses conducted in this study follow 3 scenarios: (i) no effect of SST (not shown); (ii) constant average SST at the level of the past $11 \mathrm{yr}_{\text {; }}$ (iii) increasing average SST assuming the warming trend predicted by NorESM (see text, this page). Black lines represent observed SSTs (thick) and predicted trends (thin); grey lines represent the observed trend (thick) and one realisation of modelled future SSTs (thin)

potential effects: if SST affects breeding propensity (i.e. absence/presence of adult birds during the population count), this would be visible in population models as an unlagged effect of SST. In contrast, if SST affects adult survival after breeding, the corresponding change in population size would not become evident before the population count of the following year, showing up in the population model as an SST effect lagged by 1 yr. Effects of SST on recruitment would entail even longer time lags: most kittiwakes that return to their breeding colony to breed do so at an age of 3 to $4 \mathrm{yr}$ (Coulson 2011). If breeding success (or survival of juveniles during their first winter) is affected by SST, the corresponding change in population size would therefore not be counted before the cohort affected recruits to the breeding population, i.e. 3 to $4 \mathrm{yr}$ later. In a population model, an SST effect on reproduction would thus become evident as an effect of SST lagged by the number of years that corresponds to the mean age at recruitment. Based on these assumptions, we considered SSTs around colonies at time lags of 0, 1, 3 and $4 \mathrm{yr}_{\text {; }}$ SSTs off Svalbard and in the Grand Banks area were considered at time lags of 1, 3 and $4 \mathrm{yr}$ (where the time period from autumn or winter to the following breeding season is considered to be a time lag of 1).

Estimates of SST in a future climate scenario were extracted from the Norwegian Earth System Model
(NorESM; Iversen et al. 2013), a global coupled climate model. The scenario chosen was RCP8.5 (Representative Concentration Pathway) with radiative forcing target level at $8.5 \mathrm{~W} \mathrm{~m}^{-2}$ in 2100, which is a very high baseline emission scenario leading to $\mathrm{CO}_{2}$ concentrations at $1370 \mathrm{ppm}$ in 2100 (van Vuuren et al. 2011). The RCP8.5 scenario does not include any specific climate mitigation target, corresponding to a doubling in greenhouse gas emissions by 2050 and 3fold increase by 2100 (Riahi et al. 2011). SSTs were extracted for the exact positions of each colony and for points within the wintering areas (off Svalbard, $78^{\circ} \mathrm{N}, 26^{\circ} \mathrm{E}$; Grand Banks, $51^{\circ} \mathrm{N}, 46^{\circ} \mathrm{W}$ ).

For each of these points, SSTs for the period 2006 to 2100 were used to estimate a linear trend. The period of overlap between the ERSST and NorESM data (2006 to 2011) was used to adjust the historical with the future time series to ensure that the projected SST trend started at the same value as the empirical SST data end point. For each of the 10000 PVA runs, an independent SST time series was generated. This time series consisted of white noise (zero mean and assuming the same variance as in the past, inferred from the relevant ERSST time series), added either to the mean SST of the years 2000 to 2011 or to the projected SST trend (Fig. 3).

All models were run in the $R$ environment $(R$ Development Core Team 2011). Estimates are provided with $95 \%$ confidence intervals.

\section{RESULTS}

The 5 Norwegian kittiwake Rissa tridactyla colonies studied (Runde, Sklinna, Vedøy, Hjelmsøya and Hornøya) declined steeply during the study period (Fig. 2). Beyond the decline, there was no strong temporal covariation among the colonies. If the negative trend was not removed, population counts were highly correlated (except Sklinna, all pairwise R > 0.7, all $\mathrm{p}<0.01$; Sklinna was only correlated to Vedøy). Upon removal of the trend, however, counts were uncorrelated (all $|\mathrm{R}|<0.3$, all $\mathrm{p}>0.18$ ). Nor were annual population growth rates correlated across colonies (whether de-trended or not, all $|\mathrm{R}|<0.4$, all $\mathrm{p}>0.14$ ). Population synchrony across colonies was thus virtually absent.

The long-term mean rate of decline was similar in all colonies; however, the temporal variability was much higher in some colonies (Fig. 2). This is evident from the best population model without covariates (Table 1), which assumed a common long-term intrinsic population growth rate $\bar{r}$ of $-0.055 \pm 0.026$ 
Table 1. Population models for 5 Norwegian black-legged kittiwake populations, fitted to all populations simultaneously and assuming Brownian population dynamics. Covariates used were sea surface temperatures from different ocean areas. Models are sorted by decreasing support and presented using estimates and $95 \%$ confidence intervals (CI), number of parameters $(K), \Delta \mathrm{AIC}_{\mathrm{C}}$ and model likelihood (ML). Bold: best-supported models. Models with covariates assumed a common growth rate $(\bar{r})$, and separate environmental variances $\left(\sigma_{\mathrm{e}}^{2}\right)$, in the 5 colonies (which was the best supported parameterisation of models without covariates). The 2 top models had $\mathrm{AIC}_{\mathrm{C}}$ weights of 0.40 and 0.38 , respectively. See Table S1 for densitydependent models

\begin{tabular}{|c|c|c|c|c|c|}
\hline Model: covariate (time lag, yr) & Estimate & $\mathrm{CI}$ & $K$ & $\Delta \mathrm{AIC}_{\mathrm{C}}$ & ML \\
\hline Grand Banks (3) & $b=-0.079$ & -0.132 to -0.027 & 7 & 0.00 & 1.000 \\
\hline Svalbard (1) & $b=-0.244$ & -0.404 to -0.081 & 7 & 0.12 & 0.942 \\
\hline Svalbard (1), de-trended & $b=-0.240$ & -0.450 to -0.035 & 7 & 3.60 & 0.165 \\
\hline Grand Banks (1) & $b=-0.059$ & -0.113 to -0.004 & 7 & 4.07 & 0.131 \\
\hline Grand Banks (3), de-trended & $b=-0.088$ & -0.174 to -0.004 & 7 & 4.40 & 0.111 \\
\hline Colonies (1) & $b=-0.065$ & -0.133 to +0.003 & 7 & 5.12 & 0.077 \\
\hline No covariate, common $\bar{r}$, separate $\sigma_{\mathrm{e}}^{2}$ & $\bar{r}=-0.055$ & -0.081 to -0.030 & 6 & 6.42 & 0.040 \\
\hline Grand Banks (1), de-trended & $b=-0.031$ & -0.116 to +0.052 & 7 & 8.09 & 0.018 \\
\hline Colonies (1), de-trended & $b=-0.027$ & -0.142 to +0.085 & 7 & 8.44 & 0.015 \\
\hline No covariate, separate $\bar{r}$, separate $\sigma_{\mathrm{e}}^{2}$ & & & 10 & 12.21 & 0.002 \\
\hline No covariate, common $\bar{r}$, common $\sigma_{\mathrm{e}}^{2}$ & $\bar{r}=-0.070$ & -0.106 to -0.035 & 2 & 45.64 & 0.000 \\
\hline No covariate, separate $\bar{r}$, common $\sigma_{\mathrm{e}}^{2}$ & $\sigma_{\mathrm{e}}^{2}=0.038$ & +0.027 to +0.046 & 6 & 51.89 & 0.000 \\
\hline
\end{tabular}

(corresponding to an annual reduction of $5.7 \pm 2.7 \%$ ), while the environmental variance $\sigma_{\mathrm{e}}^{2}$ differed tenfold between $0.011 \pm 0.006$ at Vedøy and $0.118 \pm 0.078$ at Sklinna. Variability was not merely a function of colony size; for instance, Hjelmsøya was a larger and more variable colony than Hornøya (correlation between mean log population size and environmental variance, $R=-0.83, p=0.080, n=5$ ).

The best model without covariates could be improved using SST as covariate (Table 1). In all cases, SST was negatively related to population growth rate. The 2 best-supported models indicated that SST during the non-breeding season had the strongest effect. According to the first model, population growth rate declined $3 \mathrm{yr}$ after a warm winter in the Grand Banks area. This time lag suggests an effect on the first-year survival of future recruits. The variance in population growth rate explained by this effect was $14 \%$ in Runde, $11 \%$ in Hornøya, $6 \%$ in Vedøy and $<1 \%$ in Sklinna and Hjelmsøya. According to the second model, population growth rate declined in years following a warm autumn southeast of Svalbard. This unlagged effect suggests an effect on adult return rate and explained a fifth of the variance in population growth rate in the 2 northernmost colonies (21\% in Hornøya, $19 \%$ in Hjelmsøya, <5\% elsewhere). When de-trending these 2 covariates, the corresponding models were somewhat poorer but still at least $2 \mathrm{AIC}_{\mathrm{C}}$ units better than models without covariates (Table 1). This indicates that the model support is not merely due to unrelated trends in population growth rate and temperature.
Of the remaining covariate models, 2 were better supported than the model without covariates, but somewhat poorer $\left(\Delta \mathrm{AIC}_{\mathrm{C}}>2\right)$ than the 2 top-ranked models. These indicated an effect of SST at the Grand Banks in the previous winter and of SST around the colonies in the previous summer (Table 1). No combinations of 2 or more covariates achieved more support than single-covariate models.

When fitting separate models to each colony, results were somewhat different (Table 2). The best models for Hornøya and Hjelmsøya contained SST southeast of Svalbard in the previous autumn. In the case of Hjelmsøya, this model could be improved by adding the previous year's SST around the colony. The latter effect was estimated to be positive after SST southeast of Svalbard was accounted for. The effect of winter SST in the Grand Banks area 3 yr earlier was only supported as a covariate to the population dynamics at Runde. The population dynamics at Sklinna and Vedøy could not be explained using the covariates considered (Table 2; cf. Table S2 in the Supplement).

Based on models without covariates, all extant colonies except Hornøya had a median time to extinction of $<90 \mathrm{yr}$ and a lower $95 \%$ confidence limit of $<50$ yr (Table 3). Estimated extinction probabilities increased when using covariate models and especially when adding a warming trend to the predicted future SST values. This pattern is evident from Fig. 4, which shows population trajectories for 1 colony under the 3 different assumptions. For all colonies, median time to extinction was significantly shorter 
Table 2. Separate population models for 5 Norwegian black-legged kittiwake populations, based on Brownian population dynamics. Covariates used were sea surface temperatures from specific ocean areas. For each colony, the best covariate model and/or other models with better support than the null model (without covariates) are shown, along with estimate, $95 \%$ confidence intervals (CI), number of parameters $(K), \Delta \mathrm{AIC}_{\mathrm{C}}$ and the variance explained $\left(\mathrm{R}^{2}\right)$. Models are sorted by decreasing support (increasing $\Delta \mathrm{AIC}_{\mathrm{C}}$ ) within each colony $\left(\Delta \mathrm{AIC}_{\mathrm{C}}\right.$ values are not comparable across colonies). See Table S2 in the Supplement for densitydependent models and de-trended covariates

\begin{tabular}{|lccccc|}
\hline $\begin{array}{l}\text { Model: covariate } \\
\text { (time lag, yr) }\end{array}$ & Estimate & CI & $K$ & $\Delta \mathrm{AIC}_{\mathrm{C}}$ & $\mathrm{R}^{2}$ \\
\hline Runde & & & & & \\
Grand Banks (3) & -0.127 & -0.259 to +0.005 & 3 & 0.00 & 0.125 \\
Null & & & 2 & 0.79 & \\
Sklinna & & & & & \\
Null & & & 2 & 0.00 & \\
Grand Banks (1) & -0.284 & -0.661 to +0.088 & 3 & 0.70 & 0.110 \\
Vedøy & & & & & \\
Null & & & 2 & 0.00 & \\
Grand Banks (3) & -0.059 & -0.145 to +0.025 & 3 & 0.65 & 0.063 \\
Hjelmsøya & & & & & \\
Svalbard (1) & -1.186 & -1.865 to -0.490 & 4 & 0.00 & 0.372 \\
$\quad+$ colony (1) & +0.589 & +0.102 to +1.068 & & & \\
Svalbard (1) & -0.733 & -1.391 to -0.090 & 3 & 1.95 & 0.192 \\
Null & & & 2 & 3.47 & \\
Hornøya & & & & & \\
Svalbard (1) & -0.310 & -0.526 to -0.084 & 3 & 0.00 & 0.210 \\
Grand Banks (3) & -0.077 & -0.151 to -0.002 & 3 & 2.78 & 0.127 \\
colony (4) & -0.140 & -0.285 to +0.005 & 3 & 3.33 & 0.110 \\
Null & & & 2 & 4.11 & \\
\hline
\end{tabular}

inter-annual variation in population growth rates, but regions and time lags differed between the colonies. Most slopes were estimated to be negative, i.e. warmer conditions were related to stronger population decrease. We ascertained that the effects of SST were not just artefacts created by uncorrelated trends by verifying the findings with detrended time series.

The oceanic regions considered had been chosen based on recent evidence of the non-breeding distribution of kittiwakes from these colonies, and the regions identified as most relevant by the population models are fully compatible with this evidence. Geolocator data singled out 2 areas as especially important for adult kittiwakes outside the breeding season (Frederiksen et al. 2012, B. Moe et al. unpubl. data): an area southeast of Svalbard, visited by kittiwakes from the northernmost colonies after the breeding season (September), and the Grand Banks, visited by birds from all colonies in winter (November to January). This explains why, in our analyses, SST under the assumption of a causal link to SST and a warming trend (reduced by as much as $56 \%$, $46 \%$, $81 \%$ and $90 \%$, respectively) than without these assumptions (Table 3, Fig. 4).

One of the models (Hjelmsøya) had covariates with opposite signs (Table 2). While this lead to increased estimates of time to extinction compared to the 1parameter model under the assumption of constant SST, the 2- and 1-parameter models did not differ under the assumption of warming (Table 3 ).

\section{DISCUSSION}

\subsection{Retrospective models of population dynamics}

Our analyses of population dynamics of 5 Norwegian kittiwake Rissa tridactyla colonies have shown that their overall rates of population decline were similar $\left(\sim 5.7 \% \mathrm{yr}^{-1}\right)$, although we found no evidence of synchrony among their annual changes in breeding numbers. SSTs in different areas of the North Atlantic explained between 6 and $37 \%$ of the east of Svalbard in September accounts for roughly $20 \%$ of population dynamics at Hornøya and Hjelmsøya, which are the colonies utilising this area the most. Models incorporating SST at the Grand Banks were better than the null model and/or the best supported covariate model for all colonies except Hjelmsøya, although this variable entered the optimal model for Runde only, where it explained some $12 \%$ of the inter-annual variation in population dynamics. Unfortunately, no geolocator data are available from Runde and Sklinna. However, based on our findings, it is unlikely that these colonies deviate from the multi-colony pattern revealed by geolocators in other colonies.

The absence of population synchrony between the colonies is somewhat surprising given the evidence that birds from several breeding colonies use the same oceanic regions during winter. This is an important finding in itself, as the degree of population synchrony may affect the extinction probability (Engen et al. 2002). The most likely explanation for the absence of synchrony is the presence of environmental noise and measurement error. 
Table 3. Modelled times to extinction of 4 Norwegian black-legged kittiwake populations, based on population viability analysis and different sets of assumptions (i.e. presence/absence of covariates and a warming trend in SST). Covariates used were sea surface temperatures from specific ocean areas. The column ' $50 \%$ ' provides the median time to extinction, and the column ' $2.5 \%$ ' provides its lower $95 \%$ confidence limit. *'Times to extinction that differ significantly from a model without covariates and warming (i.e. a median time to extinction of less than the $2.5 \%$ quartile of the corresponding null model). Bold: threshold values that correspond to Red List criteria (50\% within 10 yr: critically endangered; $20 \%$ within 20 yr: endangered; $10 \%$ within 100 yr: vulnerable)

\begin{tabular}{|lcrrr|}
\hline \multirow{2}{*}{ Model: covariate (time lag, yr) } & \multicolumn{5}{c|}{ Time to extinction (yr) } \\
& \multicolumn{4}{c}{ with a probability of } \\
& $50 \%$ & $20 \%$ & $10 \%$ & $2.5 \%$ \\
\hline Runde & & & & \\
Null & 79 & 57 & $\mathbf{4 9}$ & 40 \\
Grand Banks (3) & 45 & 35 & $\mathbf{3 1}$ & 26 \\
Grand Banks (3) + warming & $35^{*}$ & 28 & $\mathbf{2 5}$ & 22 \\
Vedøy & & & & \\
Null & 89 & 66 & $\mathbf{5 8}$ & 48 \\
Grand Banks (3) & 60 & 46 & $\mathbf{4 1}$ & 37 \\
Grand Banks (3) + warming & $48^{*}$ & 37 & $\mathbf{3 3}$ & 30 \\
Hjelmsøya & & & & \\
Null & 52 & 35 & $\mathbf{2 9}$ & 23 \\
Svalbard (1) & 35 & 26 & $\mathbf{2 3}$ & 19 \\
Svalbard (1) + warming & $\mathbf{1 0}^{*}$ & 8 & 7 & 6 \\
Svalbard (1) + colony (1) & 49 & 33 & $\mathbf{2 8}$ & 23 \\
Svalbard (1) + colony (1) + warming & $\mathbf{9}^{*}$ & 8 & 7 & 6 \\
Hornøya & \multicolumn{4}{c}{${ }^{*}$} \\
Null & 181 & 119 & 101 & 79 \\
Svalbard (1) & 94 & 72 & $\mathbf{6 4}$ & 55 \\
Svalbard (1) + warming & $18^{*}$ & $\mathbf{1 5}$ & 14 & 13 \\
\hline
\end{tabular}

trend. Kittiwakes may be hypothesised to compete with commercial fisheries, e.g. for herring Clupea harengus in the Norwegian Sea or for capelin Mallotus villosus in the Barents Sea. As far as data are available for relevant fish species, however, there have not been any increases in landings from commercial fisheries or decreases in stock sizes over the time period in question (ICES 2012).

Regarding the time lags considered, population effects of SST east of Svalbard were significant at a $1 \mathrm{yr}$ time-lag, indicating that the survival of breeding birds was affected negatively by warm conditions in that area. While the effects of mortality, intermittent breeding and permanent emigration would be indistinguishable in our models, the latter 2 processes are rather unlikely to cause the pattern. First, non-breeding should create a positive effect in the following year (lag 2), which was not observed. Second, the strong and parallel declines in all colonies rule out that there is a large degree of migration.

SST at the Grand Banks was mostly

Environmental noise may not only explain the absence of population synchrony but also be invoked as an alternative explanation for the population decline as such. Factors that have been documented to affect population dynamics in other areas and/or other species of seabirds include predation pressure (e.g. by white-tailed eagles Haliaeetus albicilla, Hipfner et al. 2012), competition with larger gulls (e.g. Oro et al. 2009) or interactions with commercial fisheries (e.g. Frederiksen et al. 2004). While such factors may have also contributed to the decline in some Norwegian colonies, they cannot explain the overall pattern. The population decline has a very similar slope in colonies experiencing predation and harrassment by eagles and those that did not (e.g. Vedøy vs. Hornøya). Populations of greater black-backed gulls Larus marinus and European herring gulls L. argentatus, which may act as competitors as well as predators on kittiwake eggs and chicks, have been declining at Hornøya and Sklinna (Norwegian Monitoring Programme for Seabirds unpubl. data). Although reliable data are missing from the other colonies, this likewise excludes competition as an explanation of the large-scale relevant if lagged by 3 yr (Runde, Vedøy and Hornøya). A time lag of $3 \mathrm{yr}$ is compatible with an effect of SST on recruitment, i.e. on the survival of immature birds (cf. Sandvik et al. 2012). Fledglings that later recruit to their natal colony will enter the population count when they first return to the breeding colony to build a nest (not necessarily to lay eggs), which in kittiwakes happens at 3 to 4 yr of age (Coulson 2011). The findings thus suggest that recruitment is poor in cohorts that experience warm conditions during their first winter after fledging. This interpretation does not involve the assumption that immatures were unaffected by environmental conditions in other years; however, consistently finding a 3 yr lag across cohorts is convincing evidence that the effect was strong enough not to be masked by the environmental conditions of the intervening seasons. On the other hand, the interpretation presupposes that immatures use the same areas as adults. Geolocator data from immatures that would allow us to test this assumption are, however, not available at present. Time lags in climate ecology can also originate from effects that are mediated through 


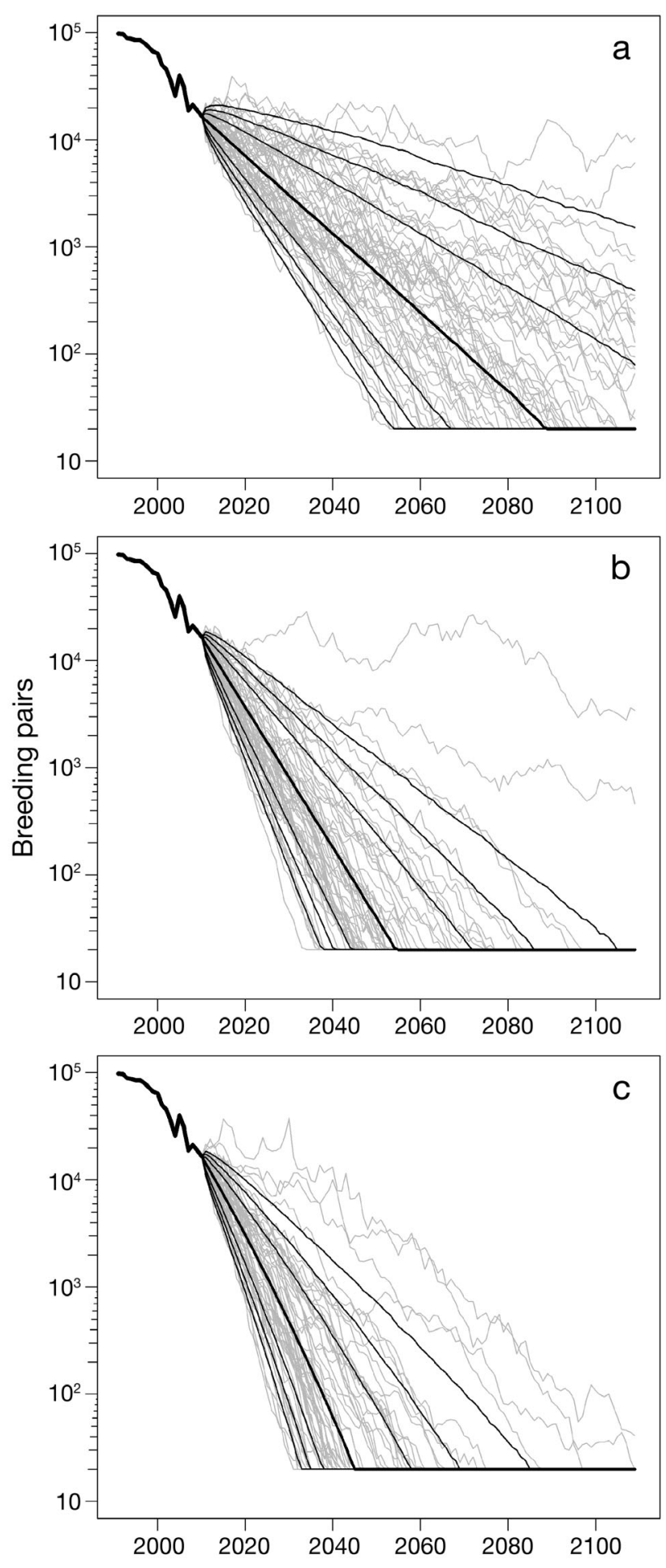

the food chain (e.g. Hjermann et al. 2004). Although this alternative explanation is less likely in this case, because kittiwakes seem to feed at a low trophic level during winter, it cannot currently be ruled out entirely.
Fig. 4. Simulated extinction trajectories of black-legged kittiwakes at the colony of Runde. Three different models are depicted (cf. Table 2 and Fig. 3): (a) population dynamics are unaffected by sea surface temperature (SST); (b) population dynamics are affected by winter SST at Grand Banks, but ocean warming is not taken into account; (c) population dynamics are affected by winter SST at Grand Banks, and ocean warming is taken into account. The figure shows actual counts for the past $20 \mathrm{yr}$ (thick line) and modelled population sizes for the next $100 \mathrm{yr}$. Thin grey lines show 60 of the 10000 trajectories simulated; black lines are the 5, 10, 20, 50 (thicker line), 80, 90 and $95 \%$ population prediction quantiles. The quasi-extinction threshold was fixed at 20 individuals. Note the logarithmic scale of the $y$-axis

The findings thus corroborate results from the North Sea, where adult survival was negatively related to SST (Frederiksen et al. 2004, 2006); in contrast, the present study did not find effects of SST on chick production (which would have resulted in a 3 yr lag of local SST), but rather on first-year survival.

A study of adult survival rates of kittiwakes from the Hornøya colony can shed some light on the likely mechanisms underlying population responses to SST. Adult survival was strongly affected by prey abundance, notably of capelin in the Barents Sea and of sea butterflies (Thecosomata) at Grand Banks (Reiertsen et al. in press). Capelin and sea butterflies are known to be important prey of kittiwakes during summer and autumn, respectively (Barrett 2007, Karnovsky et al. 2008), and may represent the causal link between SST and survival. No biotic link explaining the importance of the region off Svalbard has been identified so far (Reiertsen et al. in press).

Local conditions, i.e. summer SST around the colonies, entered the population model of Hjelmsøya but only after the effect of the non-breeding season had been taken into account (Table 2). This is the only covariate estimated to have a positive slope, indicating that adult survival was higher after warmer breeding seasons.

\subsection{Population viability analyses}

The kittiwake is currently classified as endangered in the Norwegian Red List (Kålås et al. 2010). This decision was based on Criterion A2b, because the Norwegian mainland population has decreased by almost $80 \%$ within 3 generations. According to the PVAs of the present study, most Norwegian colonies would be categorised as vulnerable $(10 \%$ extinction risk within $100 \mathrm{yr}$; see Table 3) when applying Red 
List criterion E (IUCN 2001) to each of them. In the absence of any covariate effect, Hornøya is the most viable colony, classified as near threatened $(5 \%$ extinction risk within $100 \mathrm{yr}$ ), which would change to endangered $(20 \%$ extinction risk within $20 \mathrm{yr})$ according to the PVA that includes a warming trend. The Hjelmsøya colony even crosses the threshold to critically endangered $(50 \%$ extinction risk within $10 \mathrm{yr}$ ) according to PVAs that include warming trends (Table 3). The Sklinna population, which was the smallest of the colonies studied, went extinct during the study period.

These results are only indicative because Red List criteria are not applicable to single populations (Hartley \& Kunin 2003). For example, local populations may have a high turnover rate, without the species as such being at threat (viz., if new populations are established at the same rate as other populations go extinct). There is no indication that this is the case for kittiwakes. Moreover, the negative trend was very similar in all study colonies, which covered a large part of the species' breeding range in Norway. No comparable time series are available from other Norwegian colonies, but there is no indication that other colonies are better off than the 5 colonies studied here (Erikstad \& Systad 2009).

The warming scenario may have overestimated the extinction risk (or underestimated time to extinction) for several reasons. First, the warming model chosen corresponds to a 'business as usual' scenario, which may be too pessimistic an assumption. Our main purpose was to compare 2 extreme models, one assuming constant SST and the other a drastic but realistic warming trend. As such, these 2 models represent reasonable limits that embrace the actual future trend. Most emission scenarios do, however, assume trends that are closer to the 'business as usual' scenario than to a 'no change' scenario (van Vuuren et al. 2011).

Second, the PVAs assume that the mechanisms of the past remain unchanged in the future, which, of course, is uncertain. For example, we do not yet know a great deal about the temporal stability of foraging patterns and wintering areas of kittiwakes. If they remain stable, the PVAs offer realistic viability estimates. However, at least 2 factors may decouple kittiwake population dynamics from autumn/winter SST: (1) kittiwakes may follow their main prey species as they migrate to other (presumably colder) areas, and/or (2) kittiwakes may shift to other prey. The latter may occur either because the current prey species are replaced by more warm-tolerant prey species originating from more southerly waters or be- cause kittiwakes move to areas where more warmtolerant species are abundant during winter.

A third factor that might have resulted in overestimated extinction risks is that past (actual) and future (modelled) SSTs may not be directly comparable. SST is not sampled to the same extent in all areas. A coarser sampling in Arctic waters would, for example, cause underestimation of inter-annual SST variation in the ERSST dataset. This would, in turn, result in inflated slopes in our population models, which would then overestimate the effect of warming. Further studies are needed to rule out this potential source of systematic errors.

Even when excluding a warming trend, however, the PVAs with SST covariates suggested 33 to $48 \%$ shorter median times to extinction than PVAs without covariates (Table 3, Fig. 4). Because of the high uncertainty and correspondingly wide population prediction intervals, these reductions are not statistically significant, although they certainly would be biologically so. The reasons for these drastically increased extinction risks are the negative effect of SST and the fact that even constant SST at current levels represents conditions that are considerably warmer than the long-term average (cf. Fig. 3).

Frederiksen et al. (2012) have hypothesised that the decline of kittiwakes in the North Atlantic may be due to environmental conditions at the Grand Banks, which is an overwintering area that seems to be common to the whole Atlantic population. Our findings from Runde, and to some degree from Sklinna and Vedøy, are compatible with this hypothesis. However, the decline in the 2 northernmost colonies (Hjelmsøya and Hornøya) was more closely related to autumn conditions off Svalbard, while the population declines were similar. The support for the importance of the Grand Banks area is thus somewhat equivocal.

In conclusion, although ocean warming is not the sole explanation for the decline of Norwegian kittiwake populations, it aggravates the situation considerably. Unless kittiwakes are able to switch to other foraging areas or prey, especially outside the breeding season, the populations surveyed will reach quasi-extinction within a couple of decades.

Acknowledgements. We thank all the field workers involved in monitoring kittiwake numbers over the years, none mentioned, none forgotten. The Norwegian Coastal Administration kindly allowed us to use the lighthouses on Hornøya and Sklinna as bases for the field work there. Access to the colonies was granted by the County Governors of Møre \& Romsdal, Nord-Trøndelag, Nordland and Finnmark counties. The population monitoring was mainly funded by the Norwegian Environment Agency (formerly the Norwegian Direc- 
torate for Nature Management), with initial support from the Zoological Museum at Oslo University and the Tromsø University Museum, and as part of the Norwegian seabird monitoring programme from its start in 1988. Since 2005, the study has also been an integrated part of the Norwegian seabird programme SEAPOP (www.seapop.no), which is funded as a consortium between Norwegian environmental management authorities and the Norwegian Oil and Gas Association. SEAPOP provided funds for the analysis, with additional support from the institutions of the authors. Vidar Grøtan is thanked for help with population models.

\section{LITERATURE CITED}

Barrett RT (2007) Food web interactions in the southwestern Barents Sea: black-legged kittiwakes Rissa tridactyla respond negatively to an increase in herring Clupea harengus. Mar Ecol Prog Ser 349:269-276

Bjørnstad ON, Ims RA, Lambin X (1999) Spatial population dynamics: analyzing patterns and processes of population synchrony. Trends Ecol Evol 14:427-432

Boertman D (2007) Grønlands Rødliste 2007. Grønlands Hjemmestyre, Nuuk

Burnham KP, Anderson DR (2002) Model selection and multimodel inference: a practical information-theoretic approach, 2nd edn. Springer, New York, NY

Coulson JC (2011) The kittiwake. Poyser, London

Eaton MA, Brown AF, Noble DG, Musgrove AJ and others (2009) Birds of conservation concern. 3. The population status of birds in the United Kingdom, Channel Islands and Isle of Man. Br Birds 102:296-341

Egevang C, Stenhouse IJ, Phillips RA, Petersen Æ, Fox JW, Silk JRD (2010) Tracking of Arctic terns Sterna paradisaea reveals longest animal migration. Proc Natl Acad Sci USA 107:2078-2081

Engen S, Lande R, Sæther BE (2002) The spatial scale of population fluctuations and quasi-extinction risk. Am Nat 160:439-451

Erikstad KE, Systad GH (2009) Extensive monitoring of kittiwakes in northern Norway. SEAPOP Short Report 8: 1-6, available at www.seapop.no/opencms/export/sites/ SEAPOP/no/files/short-reports/2009/2009-08_SEAPOP_ Short_Report_optimized.pdf

Esler D (2000) Applying metapopulation theory to conservation of migratory birds. Conserv Biol 14:366-372

Fosaa AM, Gaard M, Hansen J (2005) Reyðlisti. Føroya Náttúrugripasavn, Tórshavn

Frederiksen M (2010) Seabirds in the North East Atlantic. A review of status, trends and anthropogenic impact. TemaNord 587:47-122

Frederiksen M, Wanless S, Harris MP, Rothery P, Wilson LJ (2004) The role of industrial fisheries and oceanographic change in the decline of North Sea black-legged kittiwakes. J Appl Ecol 41:1129-1139

- Frederiksen M, Edwards M, Richardson AJ, Halliday NC, Wanless S (2006) From plankton to top predators: bottom-up control of a marine food web across four trophic levels. J Anim Ecol 75:1259-1268

> Frederiksen M, Moe B, Daunt F, Phillips RA and others (2012) Multicolony tracking reveals the winter distribution of a pelagic seabird on an ocean basin scale. Divers Distrib 18:530-542

Gärdenfors U (ed) (2010) Rödlistade arter i Sverige 2010. ArtDatabanken, Uppsala
González-Solís J, Croxall JP, Oro D, Ruiz X (2007) Transequatorial migration and mixing in the wintering areas of a pelagic seabird. Front Ecol Environ 5:297-301

Hartley S, Kunin WE (2003) Scale dependency of rarity, extinction risk, and conservation priority. Conserv Biol 17:1559-1570

Hipfner JM, Blight LK, Lowe RW, Wilhelm SI and others (2012) Unintended consequences: how the recovery of sea eagle Haliaeetus spp. populations in the northern hemisphere is affecting seabirds. Mar Ornithol 40:39-52

Hjermann DØ, Stenseth NC, Ottersen G (2004) Indirect climatic forcing of the Barents Sea capelin: a cohort effect. Mar Ecol Prog Ser 273:229-238

ICES (International Council for the Exploration of the Sea) (2012) Report of the Arctic Fisheries Working Group 2012 (AFWG). ICES, Copenhagen

IPCC (Intergovernmental Panel on Climate Change) (2007) Climate change 2007: impacts, adaptation and vulnerability. Cambridge University Press, Cambridge

IUCN (International Union for Conservation of Nature and Natural Resources) (2001) IUCN Red List categories and criteria: version 3.1. IUCN, Gland

> Iversen T, Bentsen M, Bethke I, Debernard JB and others (2013) The Norwegian Earth System Model, NorESM1-M. 2. Climate response and scenario projections. Geosci Model Dev 6:389-415

Kålås JA, Viken Å, Henriksen S, Skjelseth S (eds) (2010) Norsk rødliste for arter 2010. Artsdatabanken, Trondheim

Karnovsky NJ, Hobson KA, Iverson S, Hunt GL Jr (2008) Seasonal changes in diets of seabirds in the North Water Polynya: a multiple-indicator approach. Mar Ecol Prog Ser 357:291-299

Lande R, Engen S, Sæther BE (1999) Spatial scale of population synchrony: environmental correlation versus dispersal and density regulation. Am Nat 154:271-281

Lande R, Sæether BE, Engen S (2003) Stochastic population dynamics in ecology and conservation. Oxford University Press, Oxford

Lynas P, Newton SF, Robinson JA (2007) The status of birds in Ireland: an analysis of conservation concern 20082013. Ir Birds 8:149-166

> Moran PAP (1953) The statistical analysis of the Canadian lynx cycle. II. Synchronization and meteorology. Aust J Zool 1:291-298

NOAA (National Oceanic and Atmospheric Administration) (2012) Extended reconstructed sea surface temperatures, version 3b. Available at www.ncdc.noaa.gov/ersst/ (accessed 9 November 2012)

Oro D, Pérez-Rodríguez A, Martínez-Vilalta A, Bertolero A, Vidal F, Genovart M (2009) Interference competition in a threatened seabird community: a paradox for a successful conservation. Biol Conserv 142:1830-1835

Phillips RA, Silk JRD, Croxall JP, Afanasyev V, Briggs DR (2004) Accuracy of geolocation estimates for flying seabirds. Mar Ecol Prog Ser 266:265-272

> Post E, Forchhammer MC (2002) Synchronization of animal population dynamics by large-scale climate. Nature 420 : 168-171

Reiertsen TK, Erikstad KE, Anker-Nilssen T, Barrett RT and others (in press) Prey density in non-breeding areas affects adult survival of black-legged kittiwakes Rissa tridactyla. Mar Ecol Prog Ser, doi:10.3354/meps10825

R Development Core Team (2011) R: a language and environment for statistical computing, version 2.12.2. R Foundation for Statistical Computing, Vienna 
Riahi K, Rao S, Krey V, Cho C and others (2011) RCP 8.5a scenario of comparatively high greenhouse gas emissions. Clim Change 109:33-57

Sæther BE, Grøtan V, Engen S, Noble DG, Freckleton RP (2009) Critical parameters for predicting population fluctuations of some British passerines. J Anim Ecol 78: 1063-1075

Sandvik H, Erikstad KE, Sæther BE (2012) Climate affects seabird population dynamics both via reproduction and adult survival. Mar Ecol Prog Ser 454:273-284

Seavy NE, Humple DL, Cormier RL, Gardali T (2012) Establishing the breeding provenance of a temperate-wintering North American passerine, the golden-crowned sparrow, using light-level geolocation. PloS ONE 7: e34886

Smith PA, Gaston AJ (2012) Environmental variation and the demography and diet of thick-billed murres. Mar Ecol Prog Ser 454:237-249

Smith TM, Reynolds RW, Peterson TC, Lawrimore J (2008) Improvements to NOAA's historical merged land-ocean

Editorial responsibility: Mauricio Lima, Santiago, Chile surface temperature analysis (1880-2006). J Clim 21: 2283-2296

UICN France (Comité français de l'Union internationale pour la conservation de la nature), MNHN (Muséum national d'histoire naturelle), LPO (Ligue pour la protection des oiseaux), SEOF (Société d'études ornithologiques de France), ONCFS (Office national de la chasse et de la faune sauvage) (eds) (2011) La liste rouge des espèces menacées en France. Oiseaux de France métropolitaine. UICN France, Paris

van Vuuren DP, Edmonds J, Kainuma M, Riahi K and others (2011) The representative concentration pathways: an overview. Clim Change 109:5-31

Walsh PM, Halley DJ, Harris MP, del Nevo A, Sim IMW, Tasker ML (1995) Seabird monitoring handbook for Britain and Ireland: a compilation of methods for survey and monitoring of breeding birds. Joint Nature Conservation Committee, Peterborough

Wind P, Pihl S (2004) Den danske rødliste. www.dmu.dk/ dyrplanter/redlistframe/ (accessed 21 August 2013)

Submitted: August 22, 2013; Accepted: March 25, 2014 Proofs received from author(s): June 4, 2014 